\title{
El rol instrumental del proyecto urbano en la monumentalización y seguritización de la Vila Olímpica de Barcelona
}

\section{The instrumental role of the urban project in the monumentalization and securitization of the Vila Olímpica de Barcelona}

\author{
María Gabriela Navas Perrone* \\ Citar este artículo como: Navas Perrone, M. G. (2019). El rol instrumental del proyecto urbano en la monumentalización y \\ seguritización de la Vila Olímpica de Barcelona. Revista Nodo, 13(26), pp. 8-29
}

\section{Resumen}

La Vila Olímpica es la obra emblemática de la reforma urbanística que atraviesa Barcelona impulsada con las Olimpiadas de 1992. Se construyó sobre una antigua zona industrial a partir de la destrucción del patrimonio arquitectónico y el desalojo de los vecinos del barrio obrero que vivían en el sector. Este proyecto urbano permitió invisibilizar la aniquilación del pasado fabril y configurar un entorno adecuado para mantener el orden y la convivencia en el nuevo barrio. El resultado es un conjunto residencial privado, edificado para neutralizar las prácticas incívicas que atenten contra la imagen de un espacio público desconflictivizado y garantizar la seguridad de las propiedades de sus residentes. El artículo analiza el rol instrumental del proyecto urbano para mercantilizar el espacio y fortalecer políticas de control social concebidas bajo un modelo de gestión local empresarial.

Palabras clave: proyecto urbano, patrimonio, privatopía, urbanismo neoliberal, espacio público.

\section{Abstract}

The Olympic Village is the emblematic project of the Barcelona urban reform promoted with the 1992 Olympic Games. It was built on an industrial area, which implied the destruction of the architectural heritage and the eviction of the residents of the working class neighborhood that inhabited the area. This urban project made it possible to make the annihilation of the past, in order to set up an adequate environment to maintain order and coexistence in the new neighborhood. The result it is a private residential complex, built to neutralize uncivil practices that attempt against the image of a conflict-free public space and guarantee the security of its properties of its residents. The article analyzes the instrumental role of the urban project to commodify the space and strengthen social control policies conceived under a model of local business management.

Keywords: urban project, heritage, privatopia, neoliberal urbanism, public space.

Fecha de recepción: 17 de febrero de 2019 • Fecha de aceptación: 14 de marzo de 2019

\footnotetext{
* Doctora Investigadora del Grupo de Investigación en Exclusión y Control Social (GRECS) de la Universidad de Barcelona. Investigadora asociada del Centro de Etnografía Interdisciplinaria-Kaleidos, de la Universidad de Cuenca y la Facultad Latinoamericana de Ciencias Sociales (FLACSO-Ecuador). Fundadora de ANTIARQ. Miembro del Observatorio de Antropología del Conflicto Urbano (OACU) y del Instituto Catalán de Antropología (ICA). Correo electrónico: etnoproyecto@gmail.com
} 


\section{Introducción}

La Vila Olímpica se constituye como la obra emblemática de la reforma urbana que conoce Barcelona a raíz de las Olimpiadas de 1992. Ello no sólo implicó una radical transformación morfológica, sino que vino aparejada a la institucionalización de un nuevo modelo de gestión urbana de carácter empresarial (Harvey, 2007), caracterizado por la cooperación imprescindible del sector privado para el emprendimiento de la obra pública y en donde prevalece la competitividad como principal objetivo de las regeneraciones del entorno construido. Esta administración local es la respuesta política a la demanda de reestructurar el territorio acorde a la reapropiación capitalista de la ciudad, a través de la refuncionalización del suelo para la acumulación de plusvalías (Smith, 2002; Harvey, 2007; Soja, 2008). Se trata de un proceso de mercantilización del espacio, que se dio simultáneamente a la puesta en valor de un paradigma urbano reconocido como referente a nivel internacional, promovido bajo el nombre de "modelo Barcelona".

La construcción de este equipamiento olímpico que en principio estaría destinado a hospedar a los atletas participantes del evento deportivo, para posteriormente ser ofertado como un barrio para el usufructo de los barceloneses, se ejecutó en una coyuntura marcada por la transición democrática y la desindustrializción de la ciudad, que hizo posible concretar la programación que impidió la candidatura de la ciudad como sede de los Juegos

Para despejar el área de implantación de este proyecto, la entidad gestora dirigió una operación de derribo de todas las edificaciones fabriles preexistentes, que actuó como si el terreno hubiera estado vacío y deshabitado.
Olímpicos en 1924, 1936 y 1972 (Maragall, 1986, p. 170). Si bien, el proyecto 'Barcelona 92' no responde a ninguna originalidad en la agenda de gobernabilidad de los primeros ayuntamiento socialistas que lideraron la alcaldía luego de casi cuarenta años de dictadura franquista, fue la oportunidad que los líderes del Partido de los Socialista de Catalunya (PSC) estaban buscando para convertir a la Barcelona industrial en una ciudad de consumo (Tello, 1993).

Este proceso de tercerización local inmerso en el cambio global hacia una economía informacional y postfordista bajo el modelo de gestión instaurado, el mismo que implicó una participación desregulada del sector inmobiliario y bancario como agentes rectores del desarrollo urbano, se tradujo en la adaptación del territorio a las demandas de reproducción del capital. La realización de las olimpiadas fue el detonante del cambio de funciones urbanas de producción y la reconversión de antiguas instalaciones industriales de la ciudad, dentro de las cuales, destaca por su magnitud e importancia histórica, la que ocupaba el suelo en donde se construyó la Vila Olímpica. Para despejar el área de implantación de este proyecto, la entidad gestora dirigió una operación de derribo de todas las edificaciones fabriles preexistentes, que actuó como si el terreno hubiera estado vacío y deshabitado. Este vaciado del territorio, permitiría el entierro del pasado y el renacer de los símbolos de una ciudad regenerada para ocultar las contradicciones implícitas a la destrucción sin precedentes de una importante muestra de patrimonio industrial y la deliberada expulsión de los vecinos del barrio obrero.

Invertir en un aurea simbólica que revista al espacio de una memoria concordante con los sucesos reconocidos oficialmente por el Ayuntamiento, supuso la complicidad de un equipo de técnicos, dentro de los cuales el gremio de profesionales de la arquitectura tuvo un papel decisivo. El protagonismo de los arquitectos en la gestión urbana no fue fortuito, justamente porque la tarea proyectual a la que se debe su profesión, está basada en una 
construcción discursiva arbitraria que fuerza la relación entre la palabra y las cualidades formales o funcionales del proyecto, para avalar la calidad espacial de la reforma y servir de "fachada" para ocultar los intereses económicos y políticos que respaldaron su construcción. De este discurso se apropian los promotores del proyecto como estrategia de marketing urbano y las autoridades municipales para adquirir legitimidad política, puesto que al imponerse como incuestionable, permite exhibir públicamente valores ligados a la democratización de la ciudad y censurar el interés último de revalorización del suelo como factor determinante de una gestión local empresarial que entiende a la ciudad como negocio.

La instrumentalización política del proyecto urbano para la regeneración de Barcelona, es evidente en el caso de la Vila Olímpica, puesto que resultó estratégica para ocultar factores vinculantes a la tercerización del sector. A partir de esta premisa, este artículo presenta los aspectos censurados por la retórica proyectual, presentando un recuento de cómo la monumentalización del nuevo barrio invisibiliza el borrado sistemático del legado arquitectónico industrial y de la memoria de una vida de barrio que fue desarticulada tras el desalojo de sus vecinos para emprender la reforma (Navas, 2018; Navas, Delgado, Contijoch y Fabrè, 2018). Asimismo, se detalla el proceso de seguritización del conjunto habitacional que inició cuando pasó a ser habitado por los nuevos residentes, y de cómo ello vino aparejado a la implementación de ordenanzas municipales y el incremento de la vigilancia policial en el espacio público, como respuesta a la demanda de seguridad exigida por los propietarios de las viviendas. Todo ello refleja una táctica de defensa del entorno seguritizado contra expresiones de incivilidad, pobreza o manifestaciones de conflictividad social, al ser consideradas como una invasión a la propiedad privada y un riesgo para los visitantes o residentes que buscan consumir la imagen de una Barcelona modélica que ha conseguido instaurar el orden y la convivencia.

\section{Aproximación metodológica}

La metodología implementada estuvo orientada a indagar aquello que opera detrás de la imagen monumentalizada de la Vila Olímpica. El discurso promocional compartido entre los arquitectos del proyecto, el sector inmobiliario y las autoridades políticas, enaltece la tercerización del sector como posibilidad de integrar el obsoleto sector industrial a la trama urbanística de la ciudad. Sin embargo, el interés de reactivar económicamente el suelo urbano, fue determinante de la aniquilación del patrimonio arquitectónico industrial y del barrio imbricado en éste, cuya existencia no ha merecido un reconocimiento oficial en el recuento de los hechos por parte del Ayuntamiento, ni por los promotores o de los autores de la obra.

Para identificar lo velado por el proyecto urbano, se realizó en una primera instancia, observaciones sobre el terreno para analizar las cualidades del entorno e identificar los vestigios del pasado que sobrevivieron al urbicidio y que actualmente forman parte del paisaje de la Vila Olímpica. La observación implicó recorridos en el espacio público, asumiendo el rol de alguien que pasa como cualquier otro transeúnte que circula por la zona, de acuerdo a las premisas de un método etnográfico en donde prima la "observación no obstrusiva" (Delgado, 2007) y la "observación flotante" (Pétonnet, 1982). Este método consiste en permanecer disponible ante las circunstancias, dejando que la concatenación de aspectos identificados sea la referencia para descubrir las reglas subyacentes del ambiente urbano indisociable de las prácticas espaciales que tienen lugar en los exteriores del conjunto habitacional. En ese sentido, las observaciones permitieron indagar las afectaciones entre la interacción social y un entorno que consigue integrar las ruinas del pasado con los dispositivos de seguridad instalados a posteriori de su construcción. El área en donde se concentró este trabajo de campo, corresponde a los alrededores del núcleo residencial, pero también se exploraron el resto de zonas integradas a la delimitación admi- 
nistrativa de la Vila Olímpica, desde la Avenida Litoral hasta el Puerto Olímpico como su límite hacia la fachada marítima.

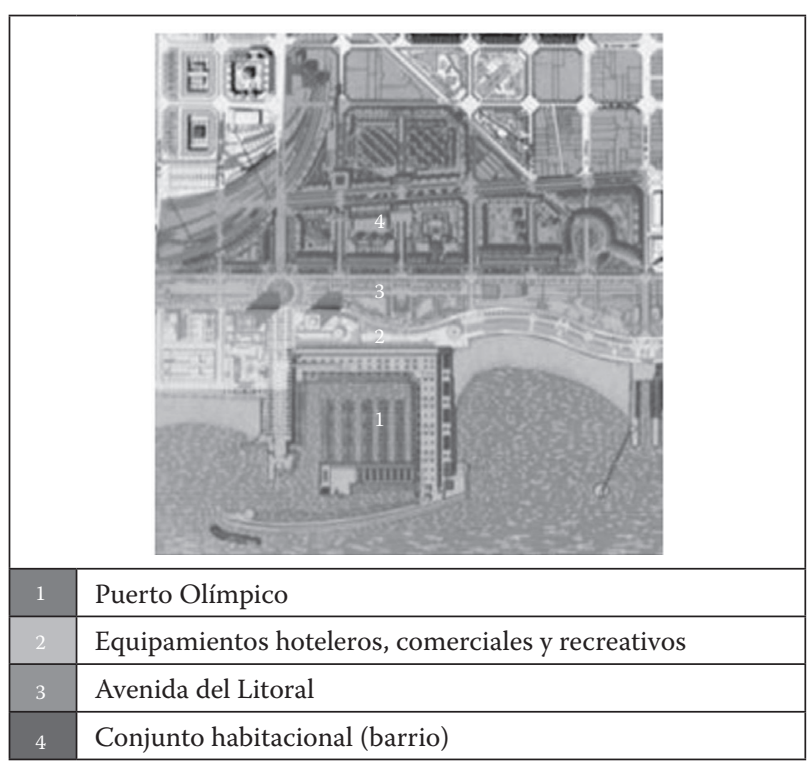

Figura 1. Delimitación del área del trabajo de campo. Zonificación de la Vila Olímpica realizada por la autora. Fuente del plano: Bohigas, Mackay, Martorell y Puigdomènech (1991)

La seguritización del paisaje urbano que cualquiera que circula por las calles de la Vila Olímpica puede constatar, decantó en el contacto con algunos residentes del barrio para comprender de primera fuente, las motivaciones que tuvieron para contratar estos servicios de seguridad privada ${ }^{1}$.

1 La identidad de los informantes se manteniene en el anonimato. Sin embargo, se esboza el perfil de las personas entrevistadas. Propietaria 1: Mujer jubilada que decidió mudarse al barrio debido a la cercanía con el lugar de su trabajo. La conocí en una ruta que se realizó sobre la historia del sector a la que asistí como espectadora. La entrevista fue concretada bajo su petición en El Centre de la Vila. Luego de nuestra conversación dimos un paseo por la 'isla' en donde vive y a lo largo de la Avenida Icària. Propietario 2: Es miembro de la Asociación de Vecinos (jubilado), a quien lo contacté en una reunión celebrada en e Casal del Barri Can Gili Nou. La entrevista la mantuvimos en el mismo casal y conversamos sobre el momento de su llegada al barrio y aspectos relacionados al funcionamiento de la entidad asociativa. Propietario 3: Hombre jubilado que desempeña la labor de presidente de escalera y participa en las reuniones de la comunidad de propietarios, por lo que concentramos en ese aspecto nuestra conversación. Me propuso encontrarnos en un restaurante de
Sobre el uso de la entrevista representacional para acceder a esta información, es preciso aclarar que se trata de una reflexión aplicada de manera complementaria a las observaciones realizadas en el espacio público; "de ahí que no podamos concebir la entrevista como algo aislable del resto de técnicas y procesos del conjunto de una investigación de campo" (Santamaría, 2000, p. 115). Las entrevistas fueron registradas mediante grabación sonora y posteriormente transcritas para ser incorporadas al hilo argumental.

Los recorridos en el espacio público se dieron a la par de un trabajo de archivo $^{2}$, que permitió contrastar las observaciones y entrevistas con la documentación encontrada y que resultó reveladora sobre la etapa inaugural de la Vila Olímpica, así como de la historia del sector, de las características arquitectónicas del patrimonio destruido y de la vida de barrio que reflejan los testimonios inventariados de los antiguos habitantes. Todos estos aspectos no han sido profundizados y en algunos casos, ni siquiera mencionados en los estudios existentes sobre este proyecto urbano. Por todo ello, el análisis de los documentos archivados, resultó ser un vía idónea de análisis etnográfico (Bosa, 2010; Gil, 2010), no sólo por la posibilidad de vincular su producción a la coyuntura política que promovió la reforma urbanística, sino porque es el único testimonio de la existencia del patrimonio industrial y del barrio obrero desparecidos. Es por ello que los registros encontrados ofrecieron "pistas para comprender qué fue lo que en determinado momento histórico se consideró oportuno guardar y se evaluó como adecuado conservar" (Muzzopappa y Villalta, 2011, p. 29).

la zona como punto de encuentro para después dirigirnos al jardín privado de su 'isla' en donde mantuvimos la entrevista.

2 Se revisaron los archivos sobre la gestión de la Vila Olímpica e historia del sector en las siguiente entidades: Centre de Documentació del Servei d`Arqueologia del Institut de Cultura; Arxiu Municipal Contemporani de Barcelona; Arxiu Intermedi de l'Arxiu Municipal Contemporani; Arxiu Històric del Poblenou; Departament de Política Territorial i Obres Públiques de la Generalitat; Fundació Barcelona Olímpica y l'Arxiu Històric del Col-legi d'Arquitectes de Catalunya. 


\section{La Nova Icària como 'lugar de memoria"}

En el terreno definido espacialmente por un perímetro triangular limitado por el mar, la avenida del Bogatell y la vía del tren que transcurría bordeando el Parque de la Ciutadella, se asentó el conjunto fabril que data de finales del siglo XIX y que se consolidó como una de las principales zonas industriales de Catalunya conocida como "Manchester catalán" (Marrero, 2003). A finales del siglo XX, este suelo había dejado de ser rentable para los grandes empresarios, en un momento en que las principales fábricas se trasladaron a la Zona Franca y la Maquinista, dando pie a un proceso de abandono que dio como resultado un bajo costo de las fincas. Sin embargo, su proximidad al centro y la cercanía a la fachada marítima multiplicaron su valor de cambio, convirtiéndolo en una reserva idónea para una recalificación urbanística que fue impulsada bajo la iniciativa de los propietarios de los terrenos. Es entonces cuando se dio el primer intento de ejecutar un plan para regenerar la fachada marítima.

En 1966 las empresas implicadas constituyeron la sociedad Ribera S.A. para solicitar a la máxima autoridad municipal, la aprobación del Plan de la Ribera (Subunidad de Planificación Urbanística, 1969) que contemplaba la remodelación de la zona comprendida entre la Barceloneta hasta la desem-

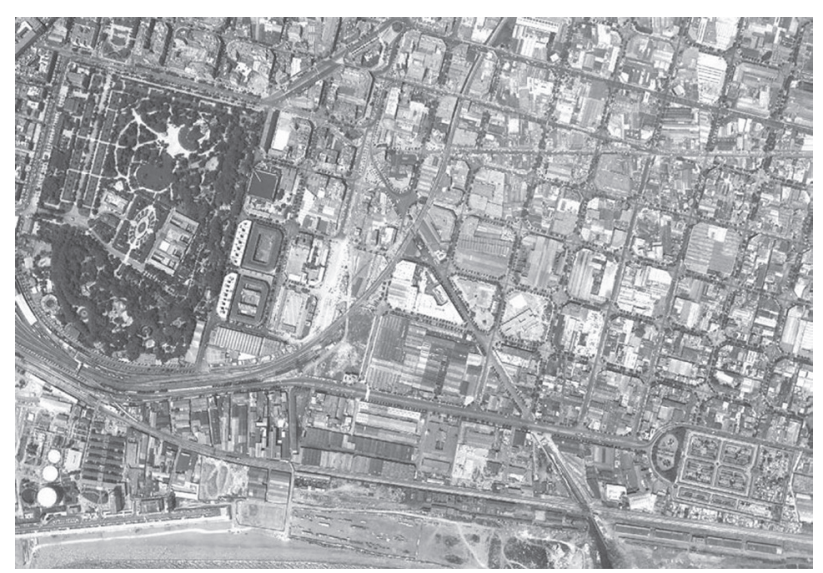

Figura 2. Vista aérea de la zona industrial en 1987, antes de su desaparición. Fuente: Caballé (2010) bocadura del Río Besós; "la Sociedad ha realizado los correspondientes estudios técnicos, económicos y sociales, para la formulación del Plan de La Ribera (...). Por todo ello a V.E. Suplican: (...) darle la tramitación que con arreglo a derecho procede y concederle en consecuencia su aprobación" (Durán, 1966). Pese a la tramitación municipal del anteproyecto, esta maquinaria inmobiliaria fue paralizada debido a la crisis económica de principios de los años 70 y a las impugnaciones conseguidas por las asociaciones vecinales, grupos empresariales y entidades profesionales que constituyeron el movimiento social que actuó como flanco de resistencia contra el urbanismo especulativo del 'desarrollismo' durante la alcaldía de Porcioles en Barcelona (Ynfante, 1974).

Veinte años después, cuando Barcelona es designada sede de los Juegos Olímpicos el 17 de octubre de 1986, se dieron las condiciones económicas y políticas favorables para impulsar la tercerización del sector. El 26 de julio de 1986, se aprobó el Plan Especial de ordenación de la fachada al mar de Barcelona en el sector del Passeig de Carles I y de la Avinguda d'Icària (Bohigas, Martorell, Mackay y Puigcomèch, 1986), que abarca el área donde se implantaría la Vila Olímpica. Para su ejecución y gestión, se creó la sociedad privada municipal Vila Olímpica, S.A. (VOSA), también encargada de la expropiación del suelo. "El Ayuntamiento dota a la sociedad de facultades suficientes para endeudarse y convertirse en titular de los terrenos expropiados y, en enero de 1988, ampliar su capital social mediante la aportación de todos los terrenos adquiridos" (Nova Icària S.A., 1988).

La estructura mixta de VOSA, hizo posible la participación de socios del sector bancario e inmobiliario como inversores del mayor porcentaje en el capital social, ello condujo los objetivos del proyecto urbano hacia la rentabilidad de los accionistas privados. Si bien la Vila Olímpica fue promovida como iniciativa municipal; "el Ayuntamiento, incapaz de promover y controlar la actuación urbanística, la pone en bandeja de oro en manos de otros grupos inmobiliarios privados" (Martí y Moreno, 1991 [1974], p. 53). Así, pese a 
las reminiscencias que comparte con el Plan de la Ribera, resultó "más fácil de llevar a la práctica sin ningún tipo de oposición” (Ídem, p. 118). Incluso previo a su aprobación, algunos medios no tardarían en hacer hincapié sobre la herencia que resonaba del Plan de la Ribera, difundiéndolo como "Vila de la Ribera" (Avui, 1986).

La incorporación de un equipo de arquitectos a la gestión urbana, se consolidó con la contratación de Oriol Bohigas como delegado del área de urbanismo del Ayuntamiento. Bohigas ocupó el cargo en 1980 durante la alcaldía de Serra (1979-1982), miembro del Partido de los Socialistas de Catalunya (PSC), y parte del siguiente período municipal liderado por Pasqual Maragall (1982-1995) sucesor del mismo partido político, quien lo nombró consejero urbanístico en 1984 y en 1985 le encargó la planificación de la Villa Olímpica que desarrolló desde el estudio MBM (Martorell, Bohigas, Mackay), junto con Albert Puigdoménech. Es en este contexto que los arquitectos ganaron protagonismo y pasaron a liderar el departamento de obras públicas; "hubo una época en la que mandaba Falange, otra en la que mandaba el Opus y, en Barcelona, hubo una época en la que mandaron los arquitectos" (Moix, 2002, p. 250).

Bohigas desde este cargo público, introdujo un nuevo método de planificación que llamó "plan-proyecto" para emprender lo que el propio arquitecto titula en un libro suyo, la "Reconstrucción de Barcelona" (Bohigas, 1985). A partir de estas bases teóricas, defiende el reemplazo del planeamiento urbano tradicional por la regeneración de la ciudad mediante proyectos puntuales, con la vocación de "higienizar el centro y monumentalizar la periferia". "Mi idea", dice Bohigas, "era que en Barcelona había la posibilidad de desarrollar una visión realista del urbanismo; una visión más interesada por la estructuración volumétrica de la ciudad que por el trazado de sus calles. Esto es, una visión de arquitecto, antes que de urbanista" (Moix, 2002, p. 30). Bajo esta premisa, asumió la misión de hacer realidad la ciudad soñada por los líderes del proyecto olímpico, apelando a la eficacia de la innovación arquitectónica. "En marzo de 1984 el alcalde Pasqual Maragall nos encargó los planes y proyectos de implantación urbana del sector en que tenía que ubicarse la Vila Olímpica", declara Bohigas, "comprendimos que era el momento de aplicar a una realidad inmediata criterios y métodos que habíamos experimentado a escalas más pequeñas y que sólo habíamos profundizado en discusiones y en investigaciones más académicas" (Bohigas et al., 1991, p. 14).

Para desplegar sin obstáculos esta obra arquitectónica, se inició el derribo de las construcciones entre agosto de 1987 y diciembre de 1988. El vaciado del territorio trajo como consecuencia el desalojo de los habitantes y trabajadores de las fábricas, así como de la destrucción de la arquitectura industrial. La impostura de un territorio vaciado de vestigios físicos y sociales, se constituyó como la principal maniobra de los primeros ayuntamientos socialistas para lugarizar una ideología de identidad, que el arquitecto debía reflejar en una regenerada volumetría y cuya eficacia dependería de la adecuada aplicación del urbanismo prescrito por Bohigas. Su discurso legitimó el vaciado del territorio como una condición primigenia de este suelo; "el área donde se decidió implantar la Villa Olímpica (...) era una especie de vacío urbano $\mathrm{y}$, por lo tanto, un lugar idóneo para hacer una renovación a fondo, implantando el primer barrio moderno junto al mar, al cual, desde el principio, ya empezamos a llamar Nova Icària" (Ibídem, p. 11). La construcción artificial de un "vacío urbano" es estratégica a la ruptura con el pasado, para marcar un antes y un después de las olimpiadas, como un acto de refundación política de la ciudad.

Hacer tabula rasa para edificar la Nova Icària, supuso la pérdida de una arquitectura industrial con valor patrimonial. "En ningún momento del proyecto de la nueva Vila Olímpica se valoró el potencial patrimonial existente (...) eran piezas realmente singulares y que hoy, difícilmente escaparían de estar entre los bienes catalogados protegidos"(Caballé, 2010, p. 6). Para paliar esta decisión, se contrató a un equipo de especialistas para que realicen el levantamiento de las edificaciones y documentación de la historia del sector 
plasmada en el Estudi històrico-arquitectònic del sector Avinguda Icària- Passeig Carles I’. Fue una iniciativa del Servicio de Actividades Arqueológicas, que propuso este trabajo de catalogación al Servicio de Protección del Patrimonio Monumental del Ayuntamiento de Barcelona, el mismo que fue financiado por la empresa gestora del proyecto, VOSA. Caballé plantea que a diferencia de otros derribos masivos reconocidos en la historia de Barcelona, la destrucción del enclave fabril ha quedado en el olvido, pese a que en volumen supera a otros sucesos destacados como el caso de la destrucción del barrio de Ribera en el siglo XVII y la apertura de la Vía Laietana a principios del siglo XX. Este discurso histórico fue respaldado por los arquitectos que participaron tanto en la concepción del proyecto urbano como símbolo que impuso un tiempo inaugural sobre el "vacío urbano", como en el registro gráfico realizado para archivar pruebas de la arquitectura destruida como legado del pasado.

Derribar, sin antes haber recogido todos aquellos aspectos que, hoy en día se entienden como indispensables para la buena comprensión de una realidad urbana, sería caer en uno de los errores más graves en la historia de la ciudad, al igual que lo sería el hecho de que la historia pusiera obstáculos a la buena ejecución de esta operación para hacer una nueva ciudad. Documentar enseguida un presente que será pasado, es imprescindible para una buena comprensión del futuro de este sector que sin duda dignifica uno de los sectores más raros y cercanos de nuestra ciudad. Esta tarea de documentación dentro de la vertiente que pertenece a los arquitectos, no es otra que realizar unos levantamientos, conscientes que serán los únicos documentos que podrán ser utilizados como muestra de una arquitectura desaparecida ${ }^{4}$. (Caballé, González, Reinald y Navas, 1988)

\footnotetext{
3 La documentación histórica fue realizada por Manuel Arranz, Reinald González, Teresa Navas, Marta Puchal y Francesc Caballé; el informe sobre la vida cotidiana de sus habitantes fue realizado por María Concepción Doncel; y el levantamiento arquitectónico corrió a cargo Xavier Güell, Montserrat Pàmies, Francesc Rabat y Alfons Llorens.

4. Traducción propia
}

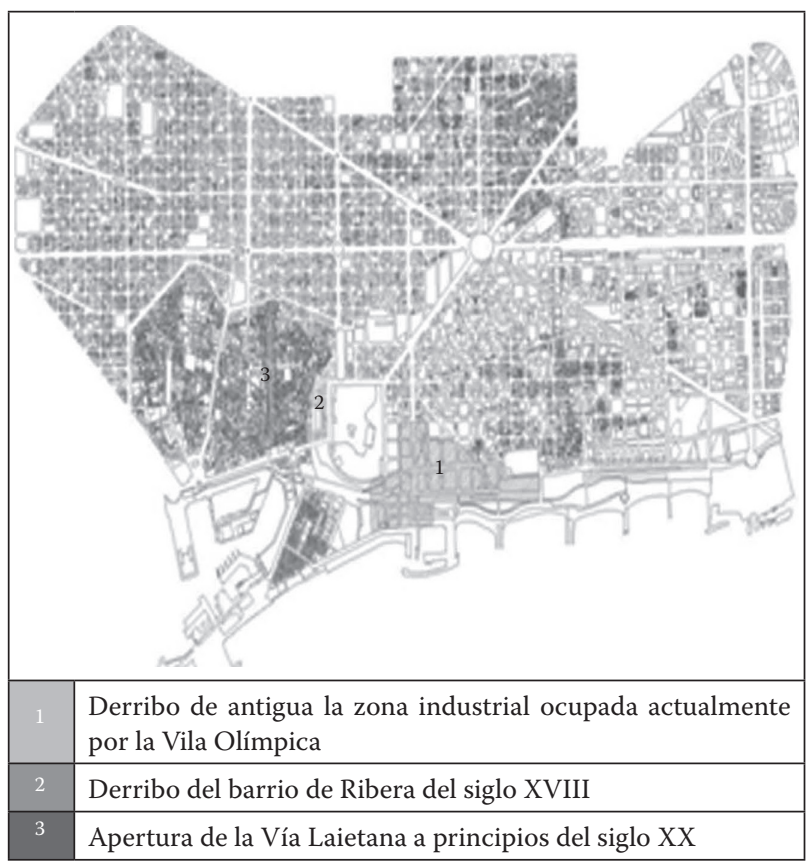

Figura 3. Extensión de los grandes derribos relazados en Barcelona por causa de transformaciones urbanísticas. Fuente: Cabellé (2010)

Todo el material documental fue archivado y actualmente se encuentra en el Centro de Documentación del Servicio de Arqueología del Instituto de Cultura y en el Archivo Municipal del Distrito de Sant Martí. El estudio contiene una exhaustiva descripción formal, funcional y constructiva, para dejar constancia de un ambiente deshabitado y configurado materialmente por la disposición de fachadas, cubiertas, chimeneas, escaleras, portones, rieles de tren, edificios de vivienda y todos aquellos componentes característicos de su arquitectura industrial, como si su existencia resultara autónoma del tejido social que lo habitaba. Pese a que uno de los informes contiene fragmentos de las entrevistas realizadas a los desalojados vecinos del sector (Doncel, 1988), sus memorias pasaron a engrosar el inventario de aquello que debía desaparecer. Según Nora, se trata de un tipo de "memoria archivística", es decir, de una demanda registradora que crece proporcionalmente a la destrucción de la memoria vivida y la necesidad de producir referencias tangibles para existir a través de ellas. Bajo esta lógica, la gestión 
del pasado en la actualidad se trata de una memoria autentificada transformada en historia, cuya ambición no es la de resaltar los hechos, sino su anulación. El borrado sistemático de todo aquello que fue deliberadamente desplazado y sepultado, fue el precedente para fundar la Nova Icària como un 'lugar de memoria' para monumentalizar el entorno urbano como un homenaje al pasado e instaurarse como verdad simbólica; "los lugares de memoria son, en primer lugar restos. La forma extrema donde subsiste una consciencia conmemorativa en una historia que la convoca porque la ignora" (Nora, 1984, p. 7).

La Nova Icària fue promovida como el proyecto que haría realidad la Icària proyectada por Cerdà en el Plano de los Alrededores de la ciudad de Barcelona, y así dar continuidad a la reforma urbanística que inició la burguesía catalana en el siglo XIX con el derribo de las murallas y la construcción del Ensanche. "El sueño de Cerdà, realizado" (Aguiló, 1992) anunciaba el Diari de Barcelona, cuando vísperas de culminar los Juegos Olímpicos, la villa de los atletas pasó a ser ocupada por los residentes

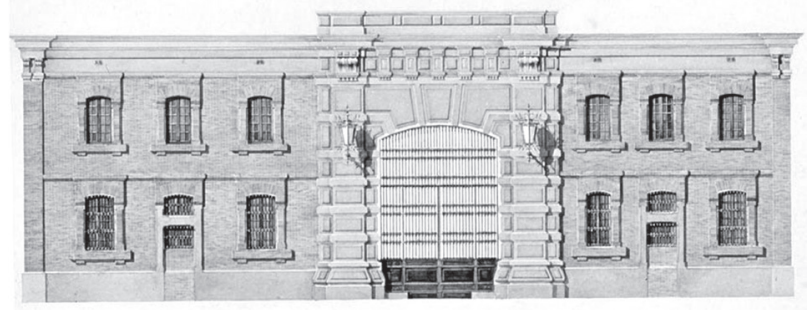

Figura 4. Levantamiento arquitectónico. Dibujo acuarelado de la fachada de la antigua fábrica Rocamora (posteriormente Motor Ibèrica). Fuente: Cabellè 2010

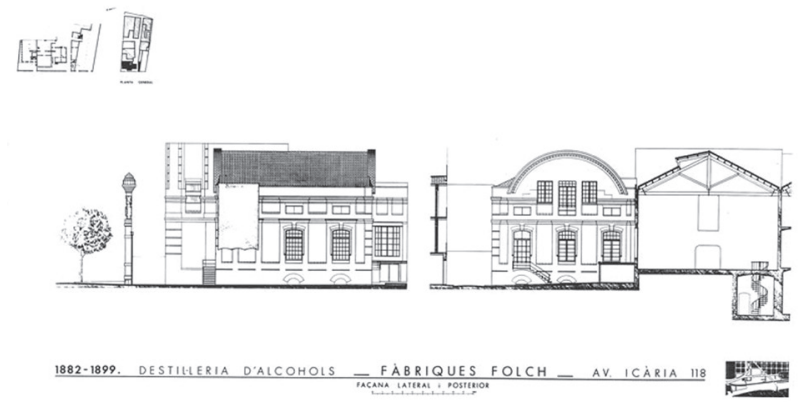

Figura 5. Levantamiento arquitectónico. Alzados y sección de fábricas Folch. Fuente: Caballè (2010) del nuevo barrio diseñado por un selecto equipo de arquitectos. Sin embargo, la impostura que supuso promover el proyecto bajo la insignia de la Icària como legado del utopismo cabetiano del siglo XIX que apostaba por una reforma espacial para la reconstrucción social acorde a los ideales de igualdad y fraternidad, fue advertida por los vecinos del Poblenou al emprender una campaña "para que la Vila Olímpica no lleve el nombre de Nova Icària (...) Los vecinos consideran que el proyecto, concebido como una zona de lujo segregada, no encaja con el socialismo utópico" (El País, 1989). Así, el nuevo barrio fue inscrito dentro de la administración municipal como "Vila Olímpica del Poblenou" y una vez que fue habitado, no tardó en dar muestras de haberse convertido en una parodia de colonia icariana, conformada por residentes cuyos vínculos comunitarios giran en torno al derecho a la propiedad privada y la defensa del civismo en el espacio público.

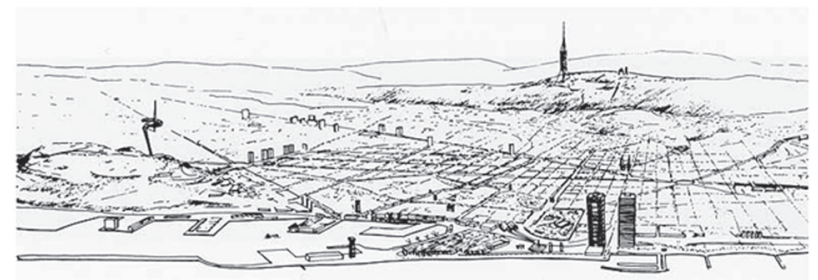

Figura 6. Boceto de reforma de la fachada marítima, la Vila Olímpica a la altura de las dos torres Fuente: Bohigas et. al 1988

\section{Vestigios del pasado en el entorno monumentalizado}

Durante las exploraciones realizadas en el espacio público de la Vila Olímpica, se pudo constatar la existencia de dos edificios y un elemento de la arquitectura industrial rescatados del urbicidio. La propuesta de refuncionalización de dichas edificaciones consta en el Plan Especial redactado por Bohigas y su equipo de trabajo. Si bien ello se concretó para los cuarteles Jaume I y Roger de Llúria, ya que fueron convertidos en una de las sedes de la Universitat Pompeu Fabra, no ocurrió lo mismo con el Centro Penitenciario de mujeres 
Wad-Ras, ya que se ha mantenido como un equipamiento penitenciario hasta la actualidad. Por su parte, la chimenea de Can Folch, es el único resto de la arquitectura industrial que fue salvaguardado, pese a la recomendación de los especialistas que realizaron el estudio contratado por VOSA, sobre la no destrucción de otras obras seleccionadas por su valor patrimonial.

La conservación de la chimenea y de la cárcel, así como la refuncionalización de los cuarteles, se integran de manera sincrónica a la legibilidad del paisaje urbano. Forman parte de la estructura morfológica que apela a la monumentalización del sector, acorde al diseño de los elementos que constituyen el proyecto urbano. Para Bohigas, autor de la Vila Olímpica y uno de los ideólogos del modelo urbano para la reconstrucción de Barcelona, el "hecho monumental" no responde exclusivamente a la rememoración del pasado, sino que, es "también, y por encima de todo, aquello que da significado permanente a una unidad urbana, desde la arquitectura que adopta un carácter representativo, hasta la escultura que preside y aglutina $\mathrm{y}$, sobretodo, hasta aquel espacio público que se carga de significaciones ${ }^{5 "}$ (Bohigas, 1985. p. 165).

Los arquitectos de la Vila Olímpica proyectaron para el nuevo barrio, varias unidades de proyectos y componentes funcionales urbanísticos, bajo un diseño cohesionado capaz de dotar al entorno construido de una abstracta homogeneidad. "Sólo al término de los proyectos ejecutivos el barrio quedaría definido (...). Estas ideas fundamentales parten, evidentemente, de un principio discutible: que es todavía posible reconstruir la ciudad europea atendiendo a su morfología" (Bohigas et al., 1991, p. 15). Este criterio de cohesión formal para integrar el nuevo barrio a la trama urbana de la ciudad, quedaría resuelto a través de la función asignada a la supermanzana que organiza la parcelación del suelo. Bohigas mantiene la continuidad del trazado cerdiano, aplicando un cambio en su escala a la 'isla' o manzana, la misma que ha

$5 \quad$ Traducción propia de servir de base para homogeneizar los diversas tipologías habitacionales y conseguir que el nuevo barrio quede integrado al entramado del Ensanche, es decir, a la ciudad preexistente, con la particularidad de que esta mímesis se conseguiría mediante esta modificación escalar. Asimismo, las supermanzanas que organizan la distribución espacial de la Vila Olímpica, son la estructura que integra espacialmente a los nuevos edificios de vivienda y las antiguas edificaciones conservadas dentro de los límites del barrio. La cuadrícula del Ensanche vincula sin contradicciones la arquitectura carcelaria de las antiguas edificaciones (cuarteles, centro penitenciario y fábrica) a la morfología del barrio caracterizado por conjuntos habitacionales seguritizados.
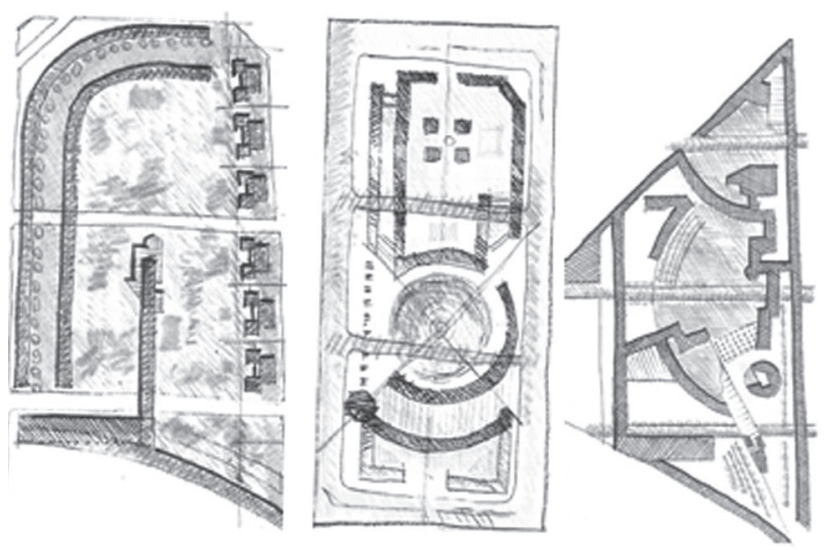

Figura 7. Esquemas para la definición de las supermanzanas. Fuente: Bohigas et al. (1988)

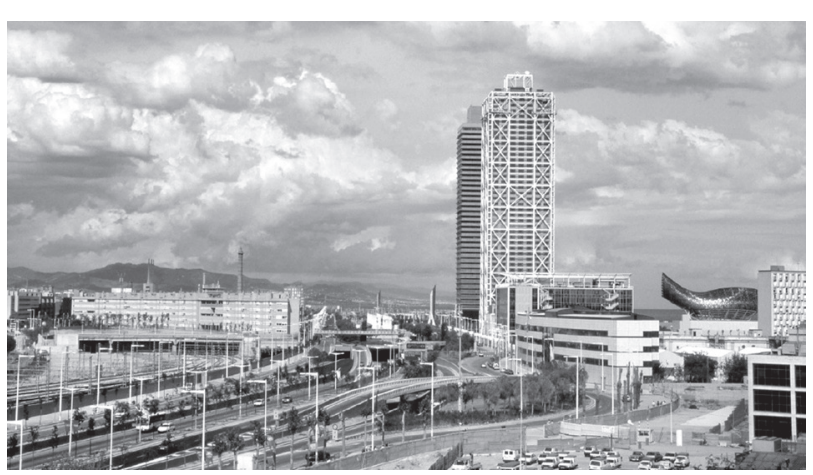

Figura 8. Vista general de la Villa Olímpica desde la Barceloneta. De la Unidad de Proyecto 6.1-6.2, sobresale la Chimenea Folch. Septiembre 1992. Fuente: Archivo Fotográfico Martí Llorens. Recuperado de: http://bcn87-92.tempusfugitvisual. com/fot-doc/final-de-obra/ 
En el extremo sureste de la Vila Olímpica, se localiza la chimenea de la antigua fábrica Can Folch, dipuesta como marca territorial de una política de la memoria que ha patrimonializado el olvido de la ciudad obrera. Fábricas Folch S.A. representaba "por su tamaño, calidad constructiva y por el número de actividades y empresas que se han desarrollado en su solar, uno de los mejores ejemplos de la arquitectura industrial en la Catalunya de finales del siglo" (Cabellé et al., 1988, ficha 0106040-011 A). La chimenea se mimetizada a la envolvente de ladrillo que recubre la fachada del proyecto urbano, como "homenaje -quizá sólo en términos de escenificación nostálgica- del viejo barrio industrial demolido, cuyos principales edificios estaban construidos con las tradicionales técnicas del muro y las bóvedas del ladrillo" (Bohigas et al., 1991, p. 115). El barrio luce como una fábrica refuncionalizada y saneada de obreros, que alberga a residentes capaces de adaptarse al reformado ambiente urbano y de responder al mantenimiento de este espacio entregado al orden, la seguridad y el civismo, como si se tratara de una factoría de ciudadanos correctos, dispuestos a contribuir incondicionalmente a los nuevos mecanismos de control implementados bajo la reforma de la Barcelona olímpica.

Hacia el extremo suroeste se localizan los cuarteles Jaume I y Roger de Llúria, que fueron refuncionalizados una vez culminados las Olimpiadas de 1992. La restauración de las edificaciones para dotarlas

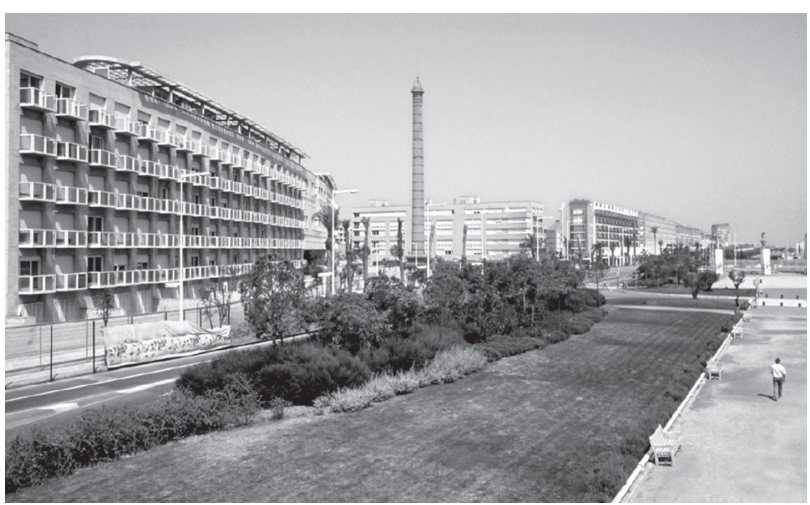

Figura 9. Unidad de Proyecto 6.1/6.2 y Chimenea Folch visto desde el Parque de las Cascadas. Agosto 1992. Fuente: Archivo Fotográfico Martí Llorens. Recuperado de: http://bcn87-92. tempusfugitvisual.com/fot-doc/final-de-obra/ de otra funcionalidad da respuesta a lo esbozado en el Plan Especial: "los dos cuarteles de la calles Wellington son ya obsoletos y es posible establecer un convenio para nuevos usos. Una posibilidad sería utilizar el solar para un gran edificio institucional, atendiendo que por ahora esta destinación es poco clara y que los edificios tienen una evidente calidad" (Bohigas, 1986, p. 9). Ambas construcciones datan de 1880 y conservaron su función militar hasta ser reformadas en 1996 para operar como el Campus de la Ciutadella de la Universitat Pompeu Fabra ${ }^{6}$ (Venteo, 2010). La incorporación de este equipamiento educativo a la Vila Olímpica atrajo la presencia de estudiantes y profesionales que circulan permanentemente por las calles del conjunto residencial.

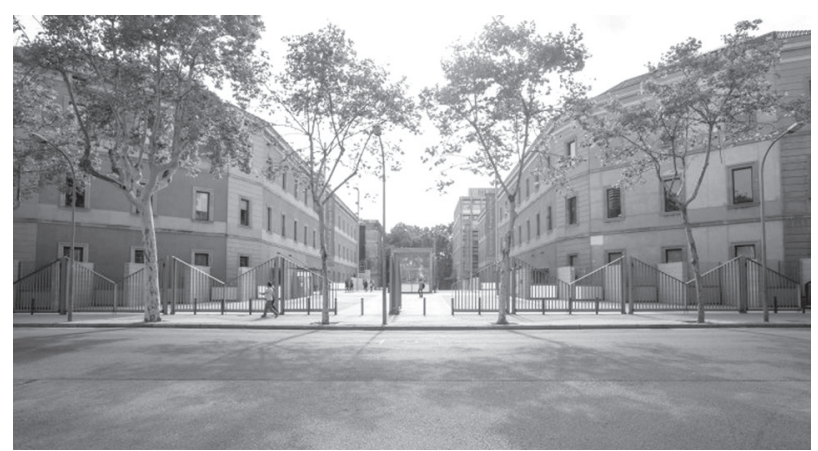

Figura 10. Campus Ciutadella de la Universitat Pompeu Fabra (Cuarteles Jaume I y Roger de Llúria). Fuente: Ayuntamiento de Barcelona

Por su parte, el edificio del Centro Penitenciario de mujeres Wad-Ras, se localiza en la calle Àlaba, hacia el extremo norte del barrio. La cárcel formó parte del paisaje fabril reconocido en los testimonios archivados de los vecinos que vivieron en esta misma calle antes de su desalojo a finales de los años ochenta. "Pues sí, vivo al lado de la cárcel (...) y los guardias (...) tocaban el claxon para saludar, ya se habían familiarizando tanto con nosotros, y actuaban eh!. (...) Hasta inclusive nos decían los policías, 'no hay en toda Barcelona un barrio tan familiar como éste"” (Doncel 1998, p. 92).

6 Tres años después es también intervenido el edificio anexo, ocupado por el Dipòsit de les Aigües, para convertirlo en la biblioteca de la institución universitaria. 
De hecho, antes de la proliferación de fábricas a partir de 1870, fue uno de las primeros terrenos reservados para la construcción de un matadero, puesto que entonces este suelo era considerado "una de las áreas preferidas por las autoridades barcelonesas para implantar servicios indeseables en la ciudad"7 (Güell y Giux coord.,1988). En 1915 este solar pasó a ser ocupado por el edificio de la Protección de menores y en 1970 fue derribado casi en su totalidad; el pabellón que se preserva hasta la actualidad es el destinado a la cárcel de mujeres Wad-Ras. Pese a que el Plan Espacial contempló la refuncionalización de este equipamiento, ello no se ha concretado y continuará funcionando como cárcel hasta el 2025, según la actualización del plan de reordenamiento penitenciario del Departament de Justícia de la Generalitat de Catalunya.

La actual prisión de mujeres en la isla definida por la Avinguda Bogatell, la calle Wad-Ras y la calle Àlaba, tendría que desaparecer, de acuerdo con las directrices ahora planteadas a la Consellería de Justíca de la Generalitat, pero el edificio actual - una discreta muestra del Modernisme- podría emplearse y albergar todos los servicios sociales que el sector necesite, especialmente un hogar de ancianos y un centro de acogida de sectores sociales problemáticos ${ }^{8}$. (Bohigas, 1986, p. 9.)

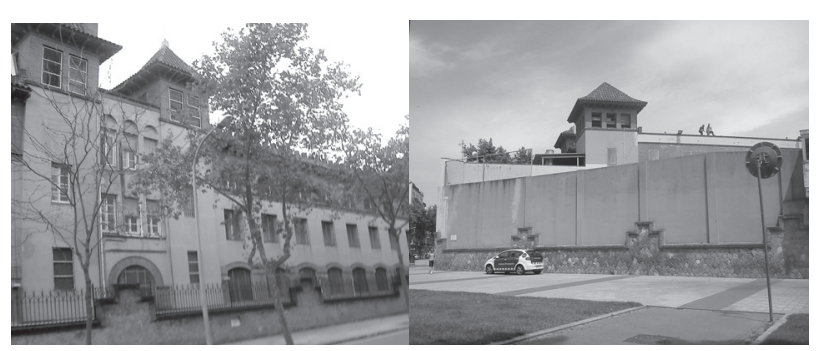

Figura 11 y 12. Centro penitenciario de mujeres Wad-Ras. Fuente: propia

7 Por este mismo motivo se construyó en las cercanías el Cementerio del Este en 1774, por ser un sector exterior a la ciudad amurallada. Este equipamiento mortuorio ha sido conservado hasta la actualidad como patrimonio de la ciudad bajo el nombre del Cementerio del Poblenou. Se encuentra junto al barrio de la Vila Olímpica, pero administrativamente pertenece al barrio del Poblenou.

8 Traducción propia
La conservación de la cárcel como parte del nuevo barrio pasa desapercibida frente a la fortificación de los conjuntos habitacionales. Cada bloque de vivienda posee un jardín central característico del modelo espacial del ensanche, pero adaptados a un sentido privativo contemplado en la concepción de los anteproyectos arquitectónicos: "su carácter será privado, cerrado mediante una reja y compartido con el jardín del resto del interior de manzana" (Sociedad Civil Alfonso Mila y Federico Correa, 1990). Este paisaje seguritizado sumado a la presencia de cámaras de video vigilancia, genera un entorno en el que los edificios de vivienda y el edificio penitenciario, adquieren una compatibilidad no explícita. Además, la distribución ortogonal de los canales de circulación propios del trazado cerdiano, generan la legibilidad adecuada para reforzar este efecto panóptico para el monitoreo de las prácticas que tienen lugar en el espacio público.

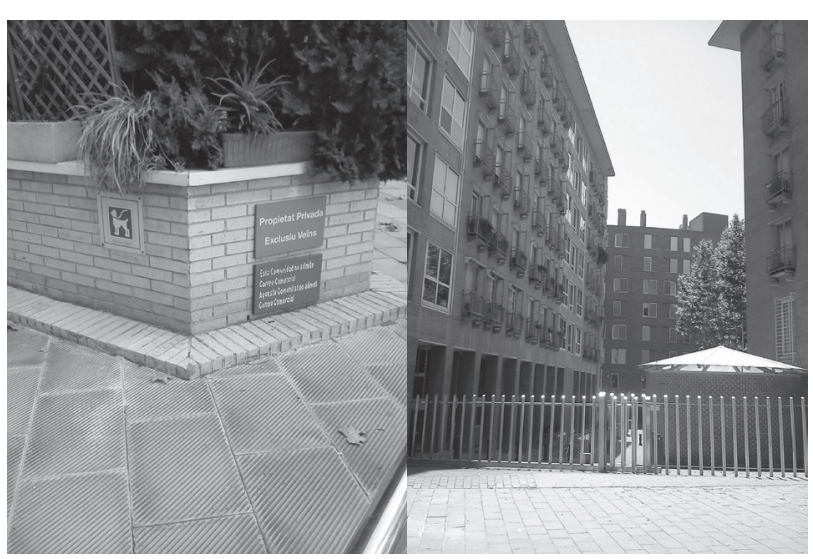

Figura 13 y 14. Seguritización de los jardines interiores en la Vila Olímpica. Fuente: propia

La urbanización del sector con la construcción de la Vila Olímpica, ha permitido extender los mecanismos de control hacia la totalidad del territorio. El proyecto urbano canaliza el dispositivo espacial idóneo para seguritizar el nuevo barrio, generando un entorno consagrado al confinamiento de los residentes en los conjuntos habitacionales y al disciplinamiento de las prácticas espaciales en el espacio público. La extensión del trazado cerdiano 
hasta el borde costero, posibilitó la recalificación del suelo para atraer funciones instrumentales y simbólicas congruentes con la monumentalización de la Vila Olímpica, de acuerdo al orden socioespacial propio del Ensanche, entendido como "reserva o imaginación del ámbito espacial de la ciudad de la burguesía" (Solà-Morales, Busquets, Font, Domingo y Gómez, 1974, p. 35).

La puesta en valor del Ensanche, responde al interés de reeditar esta tradición urbanística local que ha determinado el desarrollo de Barcelona desde el siglo XIX hasta la actualidad. En ese sentido, ello no sólo supuso una reforma morfológica, sino que reprodujo el estatuto original del urbanismo como disciplina para controlar la vida en la ciudad (Delgado, 2015). Recordemos que a Cerdá (1867) se le atribuye la autoría de la urbanística, por los planteamientos detallados en la Teoría general de la urbanización: y aplicación de sus principios y doctrinas a la reforma $y$ ensanche de Barcelona, que "fue creada de facto por Ildefonso Cerdà en 1867", como "ciencia de la organización de los espacios" (Mongin 2006, p.130). En este estudio, elabora las bases científicas de la urbanización, cuya aplicación pretende transferir nociones reguladoras de la sociedad que "sirvan para fomentar su desarrollo y vigor y para acrecentar el bienestar individual, cuya suma forma la felicidad pública" (Cerdá, 1867, p. 30). Esta dialéctica entre la reforma social y reforma espacial, es heredera de la influencia que recibió Cerdá del socialismo utópico, que apostaba por "corregir y transformar por medio de un espacio técnico el funcionamiento defectuoso de una sociedad" (Choay, 2007, p. 105-106). La adopción del planteamiento de Cerdà por parte del equipo de arquitectos autores de la Vila Olímpica, resulta indisociable de "la vocación utópica del urbanismo" (Navas, 2016), basada en la presunción de que es posible regenerar el orden social a partir de la regeneración del entorno construido. Para que ello sea efectivo, tal y como se presenta a continuación, fue necesario reforzar la seguritización del conjunto residencial.

\section{De utopía a privatopía o la Vila Olímpica como anti-barrio}

Los arquitectos de la Vila Olímpica conciben el proyecto urbano partiendo de un determinismo espacial que auguraba la producción automática de un tejido barrial a partir de la regenerada morfología que operaría como una suerte de incubadora de vida urbana. Pretendieron así, asegurar la función social del proyecto acorde a unos usos previstos en la nueva planta, pero ello no ocurrió exactamente así, puesto que los nuevos habitantes que fueron ocupando de manera paulatina las viviendas, se apropiaron de su entorno en base a un sentido compartido entre los residentes, de protección de la propiedad privada y por extensión, de fiscalización de lo que ocurra en las zonas circundantes a sus propiedades.

Pese a que la Vila Olímpica integra la lista de los 73 barrios $^{9}$ que configuran la división territorial del Ayuntamiento de Barcelona, esta tipología de barrio avalada por el discurso promotor del proyecto, no se corresponde con las situaciones que ocurren en el espacio público observadas durante las exploraciones realizadas en el sector, puesto que la carencia de apropiaciones espaciales en los exteriores de las 'islas' (o bloques de viviendas), dista mucho de representar el valor de uso que tiene la calle, entendida como un lugar de encuentro, proximidad e interacción social y como aspecto característico de la vida de barrio (Delgado, 2016). Por el contrario, las formas de sociabilidad que se puede apreciar, son más próximas a las que albergan los proyectos de urbanización, tal y como el término se emplea para aludir a conjuntos residenciales levantados en periferias urbanas para acoger a una cierta clase media. Así, la convicción de Bohigas, respecto a que el proyecto se convertirá "en un barrio

9 "La aprobación de la delimitación y la denominación de los barrios se hizo al amparo del artículo 21 de la Carta Municipal de Barcelona". Ayuntamiento de Barcelona. Disponible en: http://www.bcn.cat/estadistica/castella/terri/ (visitado el 13 de abril del 2019) 
joven, que irradie vida" y de que "la penetración vivificante será inevitable” (La Vanguardia, 1986), entra en contradicción cuando la obra abandona el plano y es construida para ser habitada por los residentes y visitantes. El problema de los conjuntos habitacionales cuando se enfrentan a la vida urbana, es comparado por Lefebvre con el problema que el biólogo tiene en el laboratorio, "éste quiere crear vida biológica; sueño o meta teórica, es el sentido de su investigación (...). Y si bien no puede hacer surgir ex nihilo la sustancia viva en una probeta, espera acercarse a este término de la ciencia y alcanzarlo algún día ${ }^{10 "}$ (Lefebvre, 1978 [1968], p. 173).

Los residentes se instalaron en el barrio atraídos por la oportunidad de vivir junto al mar, rodeados de zonas verdes, bien comunicado y cerca del centro. "Así es la Vila Olímpica”, reseñaban los carteles promocionales, "una nueva Barcelona hecha a la medida de nuestros sueños. Un barrio único. Diseñado por los más prestigiosos arquitectos y urbanistas del país. Y construido con los mejores materiales y con excelentes acabados". El mensaje era claro: "Vivir en la Vila Olímpica es la ilusión más nueva que se ha creado en Barcelona" ${ }^{11}$ (Nova Icària S.A., 1993). Sin embargo, la premura en el calendario para la construcción del proyecto, dio como resultado edificaciones con fallos estructurales y de acabados, que los nuevos

10 Lefebvre se refiere a los conjuntos urbanos concebidos por el movimiento moderno liderado por Le Corbusier en Francia durante la postguerra, advirtiendo la conflictiva relación entre el espacio concebido por los arquitectos (bajo una comprensión abstracta del espacio) y el espacio vivido y percibido por los habitantes. En el contexto catalán, es precisamente Oriol Bohigas quien retoma los postulados de la arquitectura racionalista, a través de la fundación del Grupo $\mathrm{R}$ en los años cincuenta, inspirado en el ejemplo del GATPAC (Grup d'Arquitectes i Tècnics Catalans per al Progrés de l'Arquitectura Contemporània), cuyo propuesta central era la reanudación del Movimiento Moderno; cuyo planteamiento posteriormente lo canaliza a la Escuela de Barcelona, como último episodio de la historia oficial de la arquitectura catalana antes de la reforma de la Barcelona olímpica (Piñón 1980).

11 Traducción propia. propietarios decidieron solventar demandando a la inmobiliaria Nova Icària S.A. (NISA), creada para la venta y promoción de las viviendas. "Aquí hubo unas deficiencias de construcción (...) tuvimos un pleito con la promotora Nova Icària S.A., que lo ganamos (...). Había cosas, filtraciones, pendientes mal hechas, ya no hablemos a nivel interior de cada piso, que todo el mundo lo ha rehecho" (Entrevista Propietario 3. Barcelona, abril, 2014).

La adopción del concepto del proyecto en conmemoración de la Icària de Cerdà, como el nombre distintivo de la inmobiliaria encargada de la promoción de las viviendas, Nova Icària, S.A., delata la reducción de la operación urbanística a una operación inmobiliaria que concibe a la ciudad en términos exclusivos del valor de cambio.

Dice la tradición que hace más de un siglo, en el mismo lugar donde ahora levantan la Villa Olímpica, un puñado de socialistas utópicos quiso hacer una común basada en los ideales de la libertad y el compartir, llamada Icària. Hoy, y aquí, construirán una "Copacabana" privada basada en el lujo, el negocio y la especulación. Si a sus promotores les quedara algo de decencia, no propondrían bautizarla con el nombre de "Nova Icària". "Ay! Si el Narcís Monturiol levantara la cabeza y viera lo que hacen con su sueño..." $\left(\right.$ Comissiò Icària,1986) ${ }^{12}$

Pese a los fallos constructivos, el diseño de autor y las cualidades del nuevo barrio resaltadas en el marketing del proyecto, permitieron vender todo el stock de "2048 viviendas (...) en el primer trimestre de 1996" (Carbonell, 2002, p. 310), a pesar de que fue un proceso dilatado que inició en 1990. El perfil de los potenciales compradores, correspondía al

12 La Comissiò Icària del Poblenou fue un movimiento vecinal que denunció las similitudes del el plan urbanístico de la Vila Olímpica al Plan de la Ribera. Esta plataforma se consolidó en 1986, es decir, luego de que se que se hizo público el proyecto y cuando el desalojo de los vecinos del barrio obrero estaba en proceso. Esta agrupación denunció los impactos sociales acarreados por la transformación urbanística y la exclusión de las voces críticas de los vecinos del Poblenou. 
Imatge gràfica i logotip de Nova Icária

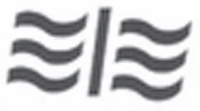

Icar cau óns les algües de la

Mediterrània i dóna el nom a la mar d'icària.

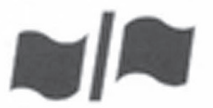

Nova Icària està a la vora de la mar

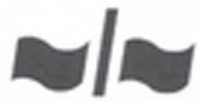

Les ones de les algües envolten eis projectes urbanístics d'edificació

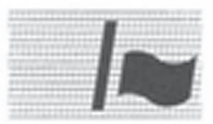

El símbol està format d'una vertical (construcción creboement, solidesa) i d'una forma ondulada (primera linia de mar)

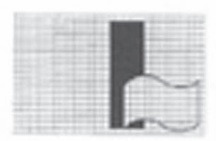

La 1 inicial d'icária accentua el seu perfil per reforcar i potenciar-ne la verticalitat

La condició mediterrània de Nova Icària hi és representada pel color blau de la forma ondulada.

Figura 15. Logotipo de Nova Icària. Fuente: Arxiu Intermedi de l'Arxiu Municipal Contemporani (Ayuntamiento de Barcelona)

de "parejas jóvenes con hijos" (Valera y Pol, 1996), que apostaron por la Vila Olímpica como lugar idóneo en donde establecerse como familia. Así, la posibilidad de contar con un espacio seguro en donde puedan jugar sus hijos o hijas, fue una de las principales motivaciones para invertir en el sector. Este aspecto fue también destacado en la campaña publicitaria: " $¿ \mathrm{Te}$ imaginas un piso pensado para tus hijos...rodeado de parques y jardines?"; "Los que tenemos 40 años, de niños, jugábamos en la calle...Hoy, nuestros hijos, también pueden hacerlo" (El País, 1992).

La ocupación de las propiedades a manera de goteo de acuerdo al ritmo de venta de las viviendas, incidió en una percepción de inseguridad compartida entre los fundadores del barrio por el hecho de estar prácticamente deshabitado. "Fue curioso, primeramente porque te encontrabas solo, yo me encontré solo allí, y vivíamos en aquella isla de 320 propietarios, a lo mejor vivíamos 50 personas al principio, yo fui de los primeros en venir. No te rías, parecía una ciudad fantasma" (Entrevista Propietario 2, abril del 2014, Barcelona). Este ambiente desolador influyó en la necesidad de resguardo del exterior que fue gestionada por las comunidades de propietarios de cada 'isla', mediante la instalación de barreras arquitectónicas en los jardines interiores para marcar el límite entre el espacio privado y el espacio público, además de la instalación de cámaras de video vigilancia y sistemas de domótica para controlar que el ingreso a cada conjunto habitacional sea exclusivo de los residentes.

Nosotros tuvimos que poner vallas porque la gente saltaba y esto era un botellón y no era el plan (...) y era bueno un descontrol total, como si fuera un sector público (...). Hay alguna isla no de la Vila Olímpica, pero cerca de aquí, que tienen el jardín abierto durante el día pero lo mantiene el Ayuntamiento y por la noche cierra, pero nosotros aquí dijimos que no, porque es muy agradable estar así, que los niños puedan venir y que no hay que vigilarles ni nada, fue una opción y para los que vivimos aquí es aceptada. (Entrevista a Propietario 3. Barcelona, abril 2014)

La intervención realizada en los jardines, se ve reflejada en la variación de la renta entre las 'islas' dentro de la misma Vila Olímpica, puesto que impacta sobre el valor de las viviendas. Hay jardines que cuentan con mayor o menor presencia de vegetación así como diferentes sistemas de vigilancia, otros tienen juegos infantiles o se ha previsto la posibilidad de colocar una piscina, etc.. "Cada isla es un mundo, es increíble, no se han compactado para nada (...) cuando yo vine a vivir me ofrecieron las casitas por diecinueve millones y veinte, $y_{i}$ las han vendido por cien!; eso te digo, que esto sólo, el dinero este, ya te hace pensar que aquí hay algo que no tiene sentido" (Entrevista 
a Propietaria 1. Barcelona, abril 2014). Incluso dentro de cada 'isla' hay variaciones, debido a los precios ofertados según la ubicación estratégica de las viviendas con vista al mar; "Así se van a crear dos tipos de vivienda, para dos clases sociales diferentes"13 (Valera y Pol, 1996).

El principio de selección natural del mercado para atraer a nuevos habitantes capaces de sostener el pago de las rentas urbanas, resultó determinante de un estilo de vida insular a diferentes escalas en la Vila Olímpica. El blindaje de los inmuebles con rejas, puertas o vallas para controlar el acceso a los jardines, responde a un sentido de protección de la propiedad privada indisociable de la búsqueda de mecanismos de seguridad. Velar por el valor de la propiedad, opera como resguardo contra las contingencias de la vida social; "dado que el individuo ya no está tomado en las redes tradicionales de dependencia y de protección, lo que le protege es la propiedad" (Castel, 2004; 23).

La actuación de la Supracomunidad creada como el paraguas de las doce comunidades de propietarios correspondientes a las doce 'islas' que integran el barrio, responde a una forma prototípica de "gobierno residencial privado" (MacKenzie, 1994) que se constituyó como el origen de la actual "Associación de vecinos y vecinas de la Vila Olímpica" (A.V.V.O.). El presidente de la entonces Supracomunidad señala que "en los comienzos de nuestra Vila, este colectivo ha sido de vital importancia para impulsar y comenzar la estructura del barrio (...) también fue la cuna donde nació la Asociación Cultural de donde después a su vez la Associació de Veïns V.O." (Giró i Castañer, 1995, p. 7). Su modus operandi restringe sus funciones a un ámbito espacial concreto, es decir, que mientras la gestión de las comunidades de propietarios se limita a cada 'isla', la administración de la asociación vecinal se concentra en el espacio público y actúa como mediadora entre los propietarios y el gobierno local para demandar las partidas presupuestarias correspondientes al funcionamiento y buen estado de la infraestructura del barrio.

13 Traducción propia
El origen de la asociación vecinal anclado en las comunidades de propietarios, es la antesala de una forma de "privatopía" (MacKenzie, 1994), es decir, de un empoderamiento público de los intereses residenciales privados, que en el marco de la vigente modalidad de gestión urbana empresarial, adquiere cada vez mayor protagonismo, ya que "constituye y facilita la privatización de la función del urbanismo en sí misma y del proceso por el que se decide dónde y cómo va a vivir la gente en las áreas urbanas" (p. 182). La gestión de esta entidad asociativa a nivel barrial orientada a vigilar que se cumpla el orden deseado por los residentes en el espacio público, reproduce el tratamiento aplicado sobre los jardines interiores, como si se tratara de una extensión de los mismos para hacer efectivo el derecho a la defensa de la propiedad privada. Ello ha tornado porosas las barreras arquitectónicas instaladas en cada 'isla' para marcar la frontera entre el espacio público y el espacio privado.

El espacio público fue promovido por los líderes políticos, la inmobiliaria y los arquitectos del proyecto, como la recompensa para los barceloneses luego de haber cedido el suelo de titularidad pública, a los bancos e inmobiliarias que comandaron su tercerización. La entrega del proyecto urbano a la rentabilidad del sector privado, fue redimida políticamente desde la incorporación del espacio público al barrio, que actualmente cuenta con "un total aproximado de 30.33 ha. que representan un 33,7\% del área total del barrio, 90 ha. Se puede considerar a la Vila Olímpica, como el barrio que tiene la mayor cantidad de espacio público por habitante $32.53 \mathrm{~m} 2 /$ hab., con respecto al resto de la ciudad" (Ayala, 2014, p. 80). Así la pérdida de la plusvalía urbana por parte del sector público se vería recompensada por parte del Ayuntamiento a la ciudadanía, en los "espacios de calidad" aledaños al conjunto residencial para el usufructo de la colectividad. Bajo esta premisa, Borja afirma que "la zona (y los entornos) de la Villa Olímpica hubiera podido ser sólo un barrio residencial de clase media", pero, es "también un gran espacio de centro recreativo popular 24 horas sobre 24 (del lado de la playa) y acoge grandes equipamientos 
culturales y universitarios (del lado de la ciudad)" (Borja, 2010, p. 226). Al respecto, es preciso señalar, que no está en cuestión la transformación del entorno construido que hizo posible la reforma de las redes de infraestructura y la incorporación de áreas verdes, playas y parques recreativos, considerados como beneficios asociados a la Vila Olímpica (Nel.lo, 2010); puesto que todos estos aspectos son la expresión morfológica de una ideología urbanística de carácter neoliberal, que es lo que en el fondo se pretende debatir, ya que tiene un impacto directo sobre la gestión misma del uso del espacio público. Como lo explica Lefebvre (2013 [1974], p. 372), “'propiedad privada' implica vida privada, es decir, privatización. Lo que a su vez implica una ideología represiva en la práctica social y viceversa, disimulándose entre sí".

La actuación de la asociación vecinal encaminada a la gestión del espacio público, incluye la tarea de exigir el cumplimiento de la ordenanza municipal ${ }^{14}$ que regula su uso para "preservar el espacio público como lugar de convivencia y civismo, en el que todas las personas puedan desarrollar en libertad sus actividades de libre circulación, de ocio, encuentro y recreo con pleno respecto a la dignidad y a los derechos de los demás". Esta normativa es el principal recurso al que apelan las comunidades de propietarios representados por la asociación vecinal, para demandar que las actividades que se dan en las zonas aledañas a sus viviendas, sean compatibles con la función residencial del barrio.

La ubicación de la Vila Olímpica, determinada por su cercanía al puerto deportivo y al paseo marítimo, en donde existe una oferta de actividades comerciales y recreativas durante todo el año, incluyendo horarios nocturnos; la convierte en el lugar de paso de todo tipo de turistas y paseantes. Ello sumado, a que es una zona que registra una baja frecuencia de uso del espacio público y en donde la interac-

14 La "Ordenança de Mesures per fomentar i garantir la convivència ciutadana a la ciutat de Barcelona" fue aprobada en el 2005. Recuperado de: http://ajuntament.barcelona. cat/hisenda/es/ordenanza-de-medidas-para-fomentar-ygarantizar-la-convivencia-ciudadana-conv (visitado el 13 de abril del 2016). ción social entre residentes se ha concentrado en los jardines privados, es lo que genera una permanente desconfianza hacia los forasteros, ya que son percibidos como una amenaza para la seguridad de los propietarios. Existe además, un consenso público de considerar a los locales que ocupan la primera línea del mar, como una zona de cultivo de prácticas consideradas incívicas denunciadas por la prensa local: "El Port Olímpic está secuestrado y más de espaldas a la ciudad que nunca. Los vecinos de la Vila Olímpica reclaman el fin del incivismo salvaje en las calles del barrio" (Márquez, 2016).

El permanente estado de alerta de residentes dispuestos a prevenir el afloramiento de cualquier manifestación de incivilidad, retroalimenta la necesidad de contratar servicios de seguridad. García, explica que "una vez satisfecha la necesidad de residir como propietario (...) la insuficiencia del 'no tener' pasa a ser insuficiencia de 'no tener seguridad"' (García, 2015, p. 210). El resultado, es un enclave seguritizado como estrategia socioespacial deliberada, en donde la diferenciación de la renta del suelo hace las veces de frontera social y consolida la segregación de la Vila Olímpica en relación al vecino barrio del Poblenou, del que originalmente formaba parte. En ese sentido, "la `seguridad` pasa a ser un valor relativo definido según la renta que permite acceder a ‘servicios de protección` o ser miembro de un enclave residencial protegido o una zona de acceso restringido" (Davis, 2003, p. 195).

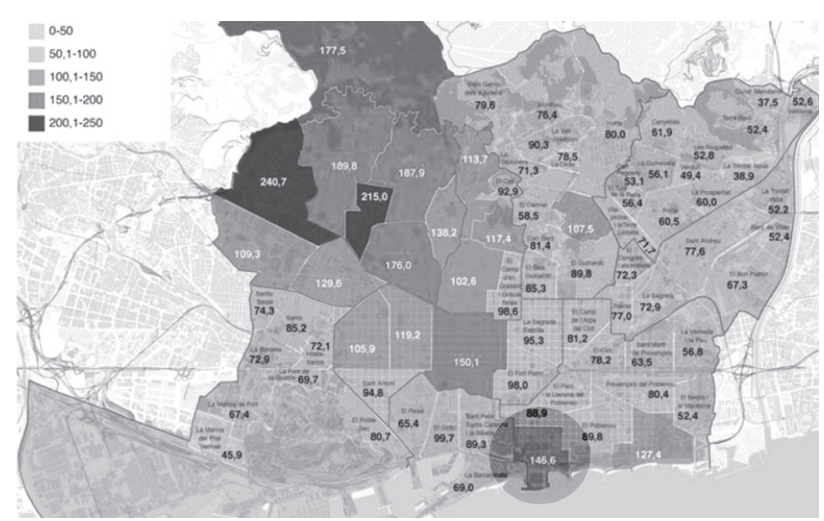

Figura 16. En este mapa se puede apreciar la diferencia de la renta y la segregación de la Vila Olímpica en relación a su barrio vecino, el Poblenou. La zona sombreada por la autora corresponde al sector. Fuente: Sobrepere, 2014. 
Este conjunto de factores hacen de la Vila Olímpica una isla para el disfrute de una clase acomodada que se protege del contacto con la otredad. Es un barrio dispuesto como refugio para eludir la conflictividad social, que ejemplifica "la obsesión por los sistemas de seguridad física $y$, colateralmente, por el control arquitectónico de las fronteras sociales" (Davis, 2003, p. 194). La seguritización de la Vila Olímpica refleja una apropiación privativa del espacio público, que tiene por objetivo proteger y vigilar en una doble operación de mantener a salvo a los residentes y activar la diferenciación entre un nosotros y los otros ajenos al conjunto habitacional.

Este tipo de conjuntos habitacionales ofertados por el mercado inmobiliario para una clase mediaalta, como es el caso de la Vila Olímpica, opera como refugios para la seguridad de ciudadanos que gestionan sus propias demandas y "pueden recrear sus utopías en una pequeña escala de gestión privada de administración, jugando con los ajustes y entornos de los espacios urbanos" (Rojo, 2015, p. 127). La puesta en escena de un barrio perfectamente diseñado debe ser complementada con dispositivos de seguridad que permitan distinguir las prácticas espaciales que resulten incompatibles con el orden espacial insaturado y que en consecuencia, deben ser expulsadas fuera de los límites de la utopía. Es un enclave seguritizado que "introduce la estetización y las arquitecturas preventivas como lógicas de diferenciación, segregación, control y exclusión" (Ávila y García, 2015, p. 22).

Garnier explica cómo los procesos de regeneración física del entorno urbano son indisociables de una preocupación seguritaria que "deberá guiar a quienes diseñan los proyectos urbanos" (Garnier, 2006 , p. 105). No casualmente, los dispositivos espaciales y el criterio de legibilidad que el proyectista prevé para los canales de circulación resultantes de la composición entre volúmenes arquitectónicos, es decir, el espacio público, son la infraestructura que reproduce el orden previsto como gobernanza urbana. Así, el proyecto urbano debe garantizar que la organización del espacio permita la vigilancia de las situaciones que se desean exhibir para contrarrestar aquellas que se deben censurar del espacio público.

El control sobre lo que ocurre en las cercanías del barrio, es supervisado por la asociación vecinal para que el gobierno local neutralice la invasión de prácticas y presencias indeseables dentro su territorio. Para dicho efecto, ha solicitado el incremento de recursos de vigilancia policial de la Guardia Urbana como acción preventiva contra las manifestaciones de incivilidad. Este gestión del riesgo responde a un paradigma seguritario neoliberal que ha sustituido el antiguo paradigma del orden público, a partir del cual emergen nuevos sujetos de la inseguridad representados por "la delincuencia 'urbana' y, categoría nueva, el 'incivismo', es decir, todo acto o comportamiento que se juzgue contrario a las normas de conducta consustanciales a la vida ciudadana" (Íbidem).

La implementación de normativas urbanas y controles policiales en el espacio público bajo este paradigma seguritario, pretende neutralizar las anomalías que el propio urbanismo neoliberal ha generado. "Un neoliberalismo que no persigue eliminar las disfuncionalidades, sino detectarlas y mantenerlas a raya, conteniéndolas dentro de un desequilibrio sostenible" (Ávila y García, 2016, p. 17). Por ello, el espacio público ha sido la fórmula empleada por el gobierno local para sostener la imagen de una ciudad que tiene "bajo la control" la desigualdad social. Pese a esta disposición de invisibilizar las contradicciones generadas por el modelo urbano, las fronteras de la Vila Olímpica son permanentemente invadidas por mendigos, prostitutas, drogadictos o turistas desacatados que merodean los alrededores y ocupan los parques de la zona, reforzando la incesante necesidad que tienen los atemorizados vecinos de protegerse. En ese sentido, "la política municipal va a remolque de la ofensiva de seguridad y de la demanda de mayor aislamiento social y espacial por parte de la clase media" (Davis, 2003. p. 198).

Todo ello, intensifica la función del proyecto urbano como frontera para la diferenciación de clase social, dispuesto morfológicamente de manera estratégica al control del espacio público ejercido por las 
comunidades de propietarios, la asociación vecinal y el gobierno local para denunciar el incivismo. El "ayuntamiento les ha prometido eliminar la zona verde de la calle de Moscou más allá de Trias Fargas e instalar una barrera con candado" (Márquez, 2016a), además de mejorar la iluminación y la limpieza, así como la refuncionalización de la zona más afectada por su cercanía a la estación de metro que opera como epicentro de los turistas y visitantes que se dirigen al Puerto Olímpico. La instalación de dispositivos espaciales para mantener a salvo a los propietarios de las viviendas frente a la conflictividad social, solventa la evasión del contacto con los invasores del barrio mediante el amurallamiento y el claustro. "La inseguridad subjetiva es hoy el 'comodín del público' para las autoridades (...) que permite al vecindario delegar en el sistema experto policial los conflictos sin afrontarlos, sin establecer puentes intersubjetivos entre personas en distintas posiciones sociales" (Ávila y García, 2015, p. 26).

Es Jane Jacobs, quien recuerda de manera enfática la importancia de la interacción social en los exteriores urbanos, como requisito irremplazable para mantener una vigilancia no regulada pero constante, al disponer de "ojos que miren la calle, ojos pertenecientes a personas que podríamos considerar propietarios naturales de la calle" (Jacobs, 2011, p. 61). La autora señala la importancia de crear soluciones urbanísticas que fomenten la ruptura del encierro de los residentes, motivándolos a contemplar la dinámica que acontece fuera de las viviendas para poblar los tramos viarios y atraer la participación de los pequeños comerciantes, ya que son "un excelente cuerpo de vigilantes y guardianes de las aceras" (Jacobs, 2011, p. 63). No es casual, que la escasa presencia de gente en los parques y aceras de la Vila Olímpica, también haya influido en el fracaso de la actividad comercial del barrio. Los escasos comercios de proximidad ubicados en las plantas bajas de los conjuntos habitacionales y los desocupados locales del Centre de la Vila (restaurantes, tiendas de ropa, farmacias, cines, etc.), concebido como el gran centro comercial del barrio para centralizar el flujo de visitantes, dan muestras de esta disfuncionalidad.
En buena medida, la permanente exigencia de seguridad por la entidad asociativa del barrio, ha sido uno de los motivos reconocidos por el gobierno local para la aprobación de un nuevo plan urbanístico para el Puerto Olímpico. Incluso, la Asociación de Vecinos y Vecinas de la Vila Olímpica, formó parte del consistorio y de los grupos municipales que participaron en la firma de un acuerdo entre el Ayuntamiento y POBASA ${ }^{15}$ para emprender la refuncionalización del puerto. La promoción de este nuevo plan liderado por la gestión de la actual alcaldesa Ada Colau, responde al mismo discurso político de "abrir la ciudad al mar" que ha acompañado a todas los planes predecesores para la regeneración del borde costero de la ciudad, desde el Plan de la Ribera hasta la actualidad. "Continuamos avanzando para que el Frente Marítimo quede plenamente integrado en la ciudad y los vecinos y vecinas recuperen su vínculo con su puerto (....) ha señalado la alcaldesa de Barcelona" (Sancho, 2018), afrontando nuevamente la contradicción planteada durante la etapa del franquismo desarrollista: “ $¿$ Abrir Barcelona al mar? o $¿$ continuar abriendo Barcelona a la especulación privada del suelo?" (Solà-Morales et al., 1974, p. 3).

\section{Consideraciones finales}

La Vila Olímpica es una pieza central en la consolidación de la red simbólica para adquirir legitimidad política, ejecutada bajo la gestión urbana empresarial instaurada con el "modelo Barcelona" desde los Juegos Olímpicos de 1992. El Ayuntamiento canalizó al flujo financiero de la reforma de la ciudad a través de proyectos urbanos que viabilicen la participación del sector público y privado, desde un discurso en defensa de la democratización que ocultó las contradicciones acarreadas con la adaptación del territorio a las demandas económicas del capitalismo tardío.

$15 \mathrm{Al}$ igual que VOSA (Vila Olímpica, S.A.), POBASA (Port Olímpic de Barcleona, S.A.) forma parte de la red de sociedades privadas municipales que se crearon para la ejecución de las obras olímpicas, en este ocasión, para la construcción del puerto y gestión del mismo hasta el 2020. 
Se constituye como la obra del equipo de arquitectos liderado por Oriol Bohigas, que asume la misión de hacer realidad la Nova Icària, y así, expandir el Ensanche hasta el borde costero. Esta reedición del Plan de Cerdá, es la evidencia de una actualización del higienismo decimonónico que en pleno siglo XX redobla esfuerzos para combatir los conflictos sociales librados por "clases peligrosas" que pongan en contradicción el milagro del renacer urbano, esta vez protagonizados por un nuevo sujeto de la inseguridad encarnado en los pobres o en las expresiones de incivilidad.

La construcción de la Vila Olímpica representa el triunfo de los intereses capitalistas sobre el territorio, para fundar un "lugar de memoria" con la violencia urbanística que significó la destrucción del patrimonio industrial y la expulsión de la población obrera que vivía en el sector. El registro documental archivado es la evidencia del olvido de este capítulo de la historia de la ciudad que hasta el día de hoy no ha merecido un reconocimiento oficial.

El proyecto urbano permitió reforzar los dispositivos espaciales de seguridad para defender los intereses que respaldaron la tercerización del suelo industrial. La primera frontera se consolidó con la variación de la renta urbana generada con la revalorización del suelo. Este efecto fortaleza es reforzado por la autogestión de las comunidades de propietarios y la asociación vecinal que contribuyen a controlar el cumplimiento de las ordenanzas urbanísticas que regulan los usos del espacio público y la construcción de infraestructuras para garantizar el mantenimiento del mismo. Así, la Vila Olímpica se consolida como una forma de privatopía, es decir un conjunto habitacional segregado del resto del Poblenou, que cuenta con un gobierno residencial privado con vinculación orgánica a la administración pública, cuyas actuaciones persiguen el objetivo compartido entre propietarios y políticos de extraer plusvalías adecuadas a la escala barrial. Representa la expresión extrema de la privatización del espacio, evidente en la mercantilización de la participación ciudadana y de los valores barriales.
Por todo lo anteriormente mencionado, la Vila Olímpica se sitúa las antípodas de un barrio, puesto que el sentido de apropiación del espacio basado en la defensa de la propiedad privada, ha normalizado la aniquilación de formas de sociabilidad que rehabiliten el valor de uso de la calle. Este caso de estudio, deja constancia del efecto depredador de la vida urbana como consecuencia de proliferación de proyectos urbanos concebidos bajo políticas de carácter neoliberal.

\section{Referencias bibliográficas}

Ávila, D. y García, S. (2015). Introducción. En Ávila, D. y García, S. (coord.), Enclaves de riesgo: Gobierno neoliberal, desigualdad y control social (pp. 15-32). Madrid, España: Traficantes de sueños.

Ayala, A. (2014). Transformación del frente marítimo de Barcelona. El caso de la Vila Olímpica del Poblenou. Evaluación de las piezas de Arte Público del barrio. (Trabajo Final para la obtención del grado de Máter en Diseño Urbano: Arte, ciudad y sociedad). Universidad de Barcelona. Barcelona, España.

Bohigas, O. (1985). Reconstrucció de Barcelona. Barcelona, España: Edicions 62.

Bohigas, O.; Mackay, D.; Martorell, J. M. y Puigdomènech, A. (1988) Tranformación de un frente marítimo. Barcelona. La Villa Olímpica, 1992. Barcelona: Editorial Gustavo Gili, S.A.

Bohigas, O.; Mackay, D.; Martorell, J. M. y Puigdomènech, A. (1991). La Vila Olímpica. Barcelona 92. Arquitectura. Parques. Puerto deportivo. Barcelona, España: Gustavo Gili, S.A.

Borja, J. (2010). Luces y sombras del urbanismo de Barcelona. Barcelona, España: Editorial UOC.

Bosa, B. (2010). ¿Un etnógrafo entre los archivos?. Propuestas para una especialización de conveniencia. Revista Colombiana de Antropología, 46 (2), pp. 497-530.

Caballé, F. (2010). Desaparece el barrio Icària, nace la Vila Olímpica. Revista Bibliográfica 
de Geografía y Ciencias Sociales, (XV, 895, 9). Recuperado de: http://www.ub.edu/geocrit/ b3w-895/b3w-895-9.htm

Carbonel, J. (2002). La Vila Olímpica, deu anys després. En Moragas, M. y Botella, M. (eds.) Barcelona: l'herencia dels Jocs (1992-2002). (pp. 309-320). Barcelona, España: Centre de Estudios Olímpica UAB, Ayuntamiento de Barcelona.

Castel, R. (2004). La Inseguridad Social ¿Qué es estar protegido? Buenos Aires, Argentina: Manantial.

Cerdà, I. (1867). Teoría general de la urbanización: y aplicación de sus principios y doctrinas a la reforma y ensanche de Barcelona. Madrid, España: Imprenta Española.

Choay, F. (2007). La utopía y el estatuto antropológico el espacio edificado. En Calatrava, J.; González, J. (eds.), La ciudad: paraíso y conflicto. (pp. 93-111). Madrid, España: Abada.

Davis, M. (2003). Ciudad de cuarzo. Arqueología del futuro en los Ángeles. Madrid, España: Lengua de trapo.

Delgado, M. (2007). Sociedades movedizas. Barcelona, España: Editorial Anagrama.

Delgado, M. (2015). Urbanismo y utopía: en pos de la ciudad celestial. [Mensaje en un blog]. Recuperado de: http://manueldelgadoruiz.blogspot. com/2015/09/urbanismo-y-utopia-en-pos-dela-ciudad.html

Delgado, M. (2016). ¿A qué llamamos "barrio"?. [Mensaje en un blog]. Recuperado de: https://manueldelgadoruiz.blogspot.com/ search?q=barrio

García, S. (2015). Artesanías securitarias: coproducción vecinal del control y su subversión. En Ávila, D. y García, S. (coords.). Enclaves de riesgo: Gobierno neoliberal, desigualdad y control social. (pp. 199-225). Madrid, España: Traficantes de sueños.

Garnier, J-P. (2006). Contra los territorios del poder. Por un espacio público de debates y...de combates. Barcelona, España: Virus.
Gil, G. (2010). Etnografía, archivos y expertos. Apuntes para un estudio antropológico del pasado reciente. Revista Colombiana de Antropología. (46, 2), pp. 249-278

Harvey, D. (2007). Espacios del capital. Hacia una geografía crítica. Madrid, España: Akal.

Jacobs, J. (2011). Muerte y vida de las grandes ciudades. Madrid, España: Capitán Swing

Lefebvre, H. (1978 [1968]). El derecho a la ciudad. Barcelona, España: Península.

Lefebvre, H. (2013 [1974]). La producción del espacio. Madrid, España: Capitán Swing.

Mackenzie, E. (1994). Privatopia: Homeowner, Associations and the Rise of Residential Private Goverment. New Haven, Estados Unidos: Yale University Press.

Maragall, P. (1986). Pasqual Maragall. Refent Barcelona. Una reflexió en veu alta sobre els grans reptes plantejats a la ciutat per tal de dinamizar el seu paper català, espanyol $i$ internacional. Barcelona, España: Planeta.

Marrero, I. (2003). ¿Del Manchester catalán al Soho Barcelonés? La renovación del barrio del Poblenou en Barcelona y la cuestión de la vivienda. Scripta Nova. Revista electrónica de Geografía y Ciencias Sociales. (VII, 146, 137). Recuperado de: http://www.ub.edu/geocrit/sn/ sn-146(137).htm

Martí, F. y Moreno, E. (1991 [1974]) Barcelona. ¿A dónde vas? Barcelona, España: Ediciones de la Tempestad.

Moix, Ll. (2002). La ciudad de los arquitectos. Barcelona, España: Anagrama

Muzzopappa, E. y Villalta, C. (2011). Los documentos como campo. Reflexiones teóricometodológicas sobre un enfoque etnográfico de archivos y documentos estatales. Revista Colombiana de Antropología. (47, 1). pp. 11-42.

Navas, G. (2016). La vocación utópica del urbanismo: el caso de la Vila Olímpica de Barcelona. Geocrítica. Cuadernos Críticos de Geografía Humana. Actas del XVI Coloquio Internacional 
de Geocrítica. Recuperado de: http://www. ub.edu/geocrit/xiv_navasperrone.pdf

Navas, G. (2018). Viatge al barri d'Icària. El patrimoni viscut d'un passat industrial arxivat. Revista d'Etnologia de Catalunya. (43).

Navas, G., Delgado, M., Contijoch, M. y Fabré, H. (2018). Viatge al barri d'Icària. El patrimoni viscut d'un passat industrial arxivat. [Mensaje en un blog]. Recuperado de: https:// observatoriconflicteurba.org/2018/04/25/ viatge-al-barri-dicaria-el-patrimoni-viscutdun-passat-industrial-arxivat/

Nel.lo, O. (2010). Les repercussions urbanistiques dels Jocs Olímpics de Barcelona. Barcelona, España: Centre d'Estudis Olímpics (UAB).

Nora, P. (1984). Les Lieux de Mémoire; 1: La République. París, Francia: Gallimard.

Márquez, C. (2016). El Port Olímpic está secuestrado y más de espaldas a la ciudad que nunca. El Periódico, 4 de julio del 2016. Recuperado de: https://www.elperiodico. com/es/sant-marti/20160704/vecinos-portolimpic-reclaman-soluciones-contra-incivismo-5246770

Márquez, C. (2016a). Sexo, borracheras y gamberrismo en la Vila Olímpica de Barcelona. El Periódico, 3 de julio del 2016. Recuperado de: https://www.elperiodico.com/es/ sant-marti/20160703/sexo-prostitucion-incivismo-vila-olimpica-barcelona-5222455

Mongin, O. (2006). La condición urbana. La ciudad a la hora de la mundialización. Buenos Aires, Argentina: Paidós.

Piñón, H. (1980). Nacionalisme $i$ modernitat en L'Arquitectura Catalana Contemporània. Barcelona, España: Edicions 62.

Pétonnet, C. (1982). L'Observation flottante. L'exemple d'un cimetière parisien. L'Homme. Etudes d'anthropologie urbaine. $(22,4)$. pp. 37-47.

Rojo, F. (2015). Transformaciones urbanas vinculadas a barrios cerrados: evidencias para la discusión sobre fragmentación espacial en ciudades latinoamericanas. Cuadernos de Geografía, Revista Colombiana de Geografía. $(24,1)$. pp. 121-133.

Sancho, J. (2018). Colau quitará el ocio nocturno del Port Olímpic y destinará más espacio para los vecinos. La Vanguardia, 6 de febrero del 2018. Recuperado de: https://www.lavanguardia.com/ local/barcelona/20180206/44583123047/colauquitara-ocio-nocturno-port-olimpic.html

Santamaría, R. (2000). La entrevista en el trabajo de campo. Revista de Antropología Social. (9). pp: 105-126.

Smith, N. (2002). New Globalism, New Urbanism: Gentrification as Global Urban Strategy. Antipode. $(34,3)$. pp. 427-450.

Sobrepere, X. (2014). Los barrios pobres de Barcelona cargan con el peso de la crisis. La Vanguardia, 31 de octubre del 2014. Recuperado de: https://www.lavanguardia.com/local/ barcelona/20141031/54418402398/barriospobres-barcelona-cargan-peso-crisis.html

Soja, E. (2008). Postmetrópolis. Estudios críticos sobre las ciudades y las regiones. Madrid, España: Traficantes de sueños.

Tello, R. (1993) Barcelona post-olímpica: de ciudad industrial a escenario de consumo. Estudios Geográficos. (54, 212). pp. 507-522.

Solà-Morales, de M., Busquets J., Font A., Domingo M. y Gómez, J. (1974). Remodelación urbana o desarrollo capitalista en el sector de la ribera oriental. Barcelona, España: Gustavo Gili, S.A.

Valera, S., Pol, E. (1996). La Vila Olímpica, integración social y urbanística como barrio de Barcelona. (Estudios de investigación becados por la Fundación Barcelona Olímpica). Barcelona: Fundación Barcelona Olímpica. pp. 183-245.

Venteo, D. (2010). Universitat Pompeu Fabra, història d'un campus urbà. Barcelona, España: Viena Edicions

Ynfante, J. (1974). Los negocios de Porcioles. Las Sagradas Familias de Barcelona. París, Francia: Monipodio. 


\section{DOCUMENTOS DE ARCHIVO}

Centre de Documentació del Servei d'Arqueologia del Institut de Cultura (Ayuntamiento de Barcelona)

Caballé, F.; Gonzàlez, R.; Navas, T. (1988). Inventari catàleg. Estudi Històric-Arquitectònic del sector Avinguda Icària-Passeig Carles I. Poblenou. (Volumen 1, 2, 3, 4, 5, 6). Barcelona, España: Ayuntamiento de Barcelona, Vila Olímpica, S.A

Doncel, M. (1988). Historia y Vida Cotidiana. El Barrio de Icària futura Vila Olímpica. Inventari catàleg. Estudi Històric-Arquitectònic del sector Avinguda Icària-Passeig Carles I. Poblenou. (9). Barcelona, España: Ayuntamiento de Barcelona, Vila Olímpica, S.A.

Güell i Giux, X. (coord.). (1988). Arquitectura. Estudi Històric-Arquitectònic del sector Avinguda Icària-Passeig Carles I. Poblenou. (7). Barcelona, España: Ayuntamiento de Barcelona, Vila Olímpica, S.A

\section{Arxiu Municipal Contemporani de Barcelona} (Ayuntamiento de Barcelona)

Subunidad de Planificación Urbanística (1969). Plan Parcial de La Ribera. Resumen de la memoria. Expediente relativo al Plan parcial de Ordenación de La Ribera y el proyecto de compensación. Barcelona, España: Unidad de Gestión Urbanística, Ayuntamiento de Barcelona.

\section{Arxiu Intermedi de l'Arxiu Municipal Contem- porani.}

(Ayuntamiento de Barcelona)

Bohigas, O.; Mackay, D.; Martorell, J. M. y Puigdomènech, A. (1986). Pla Especial d'Ordenació Urbana de la Façana al mar de Barcelona en el sector del Passeig de Carles I i Avinguda d'Icària. Barceloan, España: Ayuntamiento de Barcelona.

\section{Arxiu Històric del Poblenou}

(Ayuntamiento de Barcelona)

Aguiló, X. (1992). El sueño de Cerdà. Diari de Barcelona, 23 de abril de 1992. p. s/r.
Avui (1986). Vila de la Ribera. Diario Avui, 16 de enero de 1986. p. s/r.

Comissiò Icària (1986). Boletines informativos sobre los perjuicios ocasionados por el proyecto de la Vila Olímpica al barrio del Poblenou. p. s/r.

El País (1989). Barcelona, 18 de octubre de 1989. p. $\mathrm{s} / \mathrm{r}$.

El País (1992). Vila Olímpica. Los pisos del éxito. Anuncio publicitario de Nova Icària S.A. p. s/r.

Giró i Castañer, Jordi (1995). Comunicado firmado por el Presidente de la Supracomunidad. Revista Vila Olimpica. No. 6. Julio y Agosto. Associació Cultural i Esportiva de la Vila Olímpica. p. 7.

La Vanguardia (1986). La reordenación urbanística del Poblenou para los J.J.O.O. y su futuro inmediato, explicada por el autor del proyecto. La Vanguardia, 21 de diciembre. pp. 26-27.

Nova Icària S.A. (1988). Informe sobre la constitución de la Sociedad Nova Icària S.A., firmado por Rosa Fornas Prat, Jefe de Servicios Jurídicos, en julio de 1988. p. s/r.

Nova Icària S.A. (1993). Boletín promocional de las viviendas del barrio. Consejo de Adminitración. Documentación Sr. Ramón Boixadós Malé. p. $\mathrm{s} / \mathrm{r}$.

Arxiu Històric del Col-legi d'Arquitectes de Catalunya (Barcelona)

Sociedad Civil Alfonso Mila y Federico Correa (1990). Proyecto ejecutivo de la Unidad de Proyecto U.P. 7.2. del Plan Especial "Vila Olímpica". Memoria descriptiva. p. s/r.

Departament de Política Territorial i Obres Públiques de la Generalitat

(Generalitat de Catalunya)

Durán, P. (1966). Carta de Ribera S.A. en nombre de su presidente Pedro Durán Farell, dirigida al alcalde franquista José María Porcioles. P. S/R. 